\title{
Evaluation Setup Process on Rotogravure Printing Machine in Oder to Reduce Setup Time
}

\author{
Kadex Widhy Wirakusuma ${ }^{1}$ and Moses LaksonoSinggih ${ }^{1}$
}

\begin{abstract}
The company carries out various ways to be able to meet customer demand quickly, one of which is to speed up the production process. In the printing process, the company encountered a problem, one of which was the high downtime caused by the setup process. The standard setup time determined by the company is 150 minutes but in fact the time required is 211.33 minutes. This shows that there are inefficient methods applied by the company. In this study, we will evaluate the work method to get errors so that the setup duration becomes high. This study will draw on the Modified Cooper Harper Scale and Single Minute Exchange of Dies (MCH-SMED) method to balance the workload between operators so that the setup time can be reduced. The MCH method is used to analyze the mental and physical workload on an operator based on a tree decision scale so that it can balance the workload between operators. SMED is used to identify on-line and off-line operations in the setup process. This study aims to produce a comparison of the standard setup times that have been set by the company and after evaluating the integration process of printing machine setup (MCH-SMED). The results of this study are to obtain a new sequence of operations that can reduce the duration of setup time to 143.19 minutes or be able to reduce the setup time by $32 \%$.
\end{abstract}

\section{Keywords-Setup Time, SMED, MCH, Productivity.}

\section{INTRODUCTION}

Today,the development of manufacturing systems is undergoing rapid changes due to the complexity of the manufacturing process and also changes in demand that can change so rapidly [1]. To ensure that they remain competitive, producers must be able to maintain the speed of service to consumers. To increase the speed of service to consumers, companies must be able to minimize problems in the production process, one of which is to accelerate the duration of the setup, so as to be able to meet consumer demand so that satisfaction can be achieved [2].

Setup time is the time needed to prepare for work in the next process [3]. The time can be in the form of time to prepare work equipment, time to prepare the machine, and most of it is done when the machine is not operating, the benefits obtained are increasing production capacity, reducing lead time, increasing customer responsiveness, reducing batch size, reducing inventory, reducing waste, and increase flexibility in the production process [4]. So that by reducing setup time significantly it can affect

\footnotetext{
${ }^{1}$ Kadex Widhy Wirakusuma and Moses Laksono Singgih are with Department of Industrial Engineering, Institut Teknologi Sepuluh Nopember, Surabaya, Indonesia. Email: moseslsinggih@ie.its.ac.id.
}

production time so as to increase production throughput [5].

Many research have been conducted to reduce the duration of the setup duration as done [6], [7]. However, there is no research considering the operator workload factor as an important parameter that can affect the duration of the setup. Therefore, workload factors both physical and mental will be considered as one of the parameters that can affect the high duration of setup time. The purpose of this research is to identify the operating time of the existing condition setup, identify the largest workload weights, describe the different alternatives, and get a comparison of the time of the existing condition setup and after making improvements.

This study will focus on reducing the duration of setup in the operation of the rotogravure printing machine setup by operators by integrating two methodologies, namely Single Minute Exchange of Die (SMED) with Modified Cooper Harper (MCH) Scale. This paper is structured as follows: Part II is the Literature Review related to research. Part III is the Research Methodology, Part IV Results and V Conclusion.

\section{LITERATURE RIVIEW}

\section{A. Setup Time}

Setup time is one of the important parameters used in the manufacturing industry and is a form of input needed for each machine or workstation [8]. The setup involves all activities starting from preparing the machine or workstation to carrying out the next operation, and the type of work, type of machine and both [9]. Reduction Setup theory or method used to shorten setup time. The time spent concerns the timing of machine component settings, the time of providing work equipment, and so forth. There are two types of setups that are the first major setup where setup is done to produce product components of various types, minor setup is a setup that is performed to produce product components that have the same type.

There are several advantages of simplifying the setup process such as being able to improve product quality. Setup errors have the potential to cause damage in each unit in one batch, with standard setup procedures so trial and error and inspections can be eliminated so as to reduce setup time, simple setup procedures can reduce operator working hours and operator skill levels for setup can eliminate scrap produced. As a result, the costs associated with setup can be reduced. With a short setup time, 
manufacturing activities are more flexible to adapt to changing demands. A simple setup process does not require an expert operator to setup this to reduce operator idle time. Therefore, setup experts only work for difficult setup activities or make better setup procedures. Lead times can be reduced because the combination of a lot of size is small and the time wasted waiting for setup can be reduced, if the time used to setup short, the process of variability can occur. Substitution of tools and fixture are things that influence each other during setup time [10].

Setup Reduction can handle problems related to frequent changes in demand so that it requires an improvement in terms of improving equipment, availability and elimination of waste in setup changes. Based on the principle of Lean Production, value added activities are activities that must be put forward so as to produce high productivity. Setup Reduction can eliminate waste by maximizing better operator time, reducing lead time, inventory storage space and reject rates. Reduction setup time makes cycle time per part more effective so it can reduce the cost of small-batch products and make small batch sizes possible. To measure the impact of setup time reduction, the first step that can be done is to evaluate the impact of reduction setup by several indices such as: reduction in setup time, increased availability of equipment, saving in labor costs from reduction setup, batch size reduction, economic penalty, and overall equipment effectiveness (OEE) [4].

\section{B. Single Minute Exchange of Die (SMED)}

Single Minute Exchange of Die (SMED) is a methodology developed by Shingo in 1995 to reduce setup time so as to increase the efficiency of the production process. SMED is one of the improvement methods in lean manufacturing.

Some advantages of the application of the SMED methodology are that it is easy to use so that it helps quickly identify problems. Another contribution of the SMED method is to be able to significantly solve a problem so that it helps an organization to make a decision. If the SMED system is able to be implemented properly, the setup process can be done quickly, besides that the setup process can be done more simply and easily.

The SMED application is able to identify operations that are on-line and off-line. On-line setup is an operation that can only be done when the engine is down, while the online setup operation that can be performed when the machine is in production [10], on-line and off-line setup involves various operations such as preparation, adjustment, material checking, installation, arrangement, measurement, trial and calibration.

When compared to the Total Productive Maintenance (TPM) tools, the benefits of SMED are basically the same as TPM, namely increasing the flow of production processes (improve flow), lower supply, and improving product quality. TPM focuses on reducing unplanned downtime, while SMED focuses on reducing downtime planned due to the changeover process. The faster the time taken into account for the engine changeover from one product to another means that more time is allocated to the production process so that it can increase product output.

\section{Modified Cooper Hoper (MCH) Scale}

Modified Cooper Hoper (MCH) Scale is a method used to measure workload by considering a combination of mental and physical workload using the decision tree rating scale. Initially $\mathrm{MCH}$ was used to measure pilot workload in aircraft handling. The Cooper Harper Scale was modified [11] based on the assumption that there is a direct connection between the level of difficulty between aircraft control capabilities and pilot workload.

Define a scale in the burden of workloads, namely 1-10. Scale 1 is defined as the minimum effort that must be spent. Workload that is not included in the minimum but acceptable category includes a score of 2-3. Furthermore, the workload that requires more effort to the maximum is included in the score of 4-10 [12]. MCH is efficient and suitable for use in a variety of work fields, especially in human-machine work systems that require perception, monitoring, evaluation, communication, and decision making from humans.

The advantages of the MCH method: Easy to use, and do not require additional equipment, Size of Non-instrusive workload, validation in determining the scale on the Cooper Hooper method is quite high, can be modified to measure workload in various domains, Data generated using the $\mathrm{MCH}$ Scale method easy to analyze. The disadvantage of the MCH Scale method is that it can only be used for manually done tasks. Data is collected after the post-trial. So, there are limitations such as correlation with performance. Unable to report past workloads, and Unidimensional

\section{METHOD}

The methodology in this study starts from collecting data relating to the identification of printing machine processes, describing the flow of the setup process in OPC, and collecting historical data relating to standard setup time, setup frequency, downtime, and available time. The next stage is the data collection method that is carried out by conducting direct observation, brainstorming, and operating documentation that supports the research process, the next stage is processing data on the data that has been collected to recalculate the operating time of the existing condition setup, measuring the operator's workload time, determine the number of operations, and calculate performance. The next step is to measure the weight of the workload using the modified Cooper Harper Scale, modification based on previous research. The modified Scale Cooper Harper results in Figure 1. Analysis Cooper Harper method is used to determine the operating weight of the operation carried out by the operator and also classifies work weight into 3 characteristics of under load, optimal 
load, and over load workload. The next step is to analyze the types of setup operations in on-line and off-line setup using the SMED method. SMED is used to determine the type of operation that can be done off-line setup based on the results of the classification of workloads carried out in the previous stages. The last step is to evaluate the work method carried out by the operator using a map of the left and right hands map approach based on motion economics. This approach is used because in more setup processes dominance is done manually so that the operator's role is very much in the setup process itself. The next stage is an analysis of the results of data processing that has been carried out such as analyzing the existing conditions, analyzing the $\mathrm{MCH}$, analyzing the SMED, and analyzing the improvement alternatives. Figure 1 explains the research methodology that will be carried out in this study.

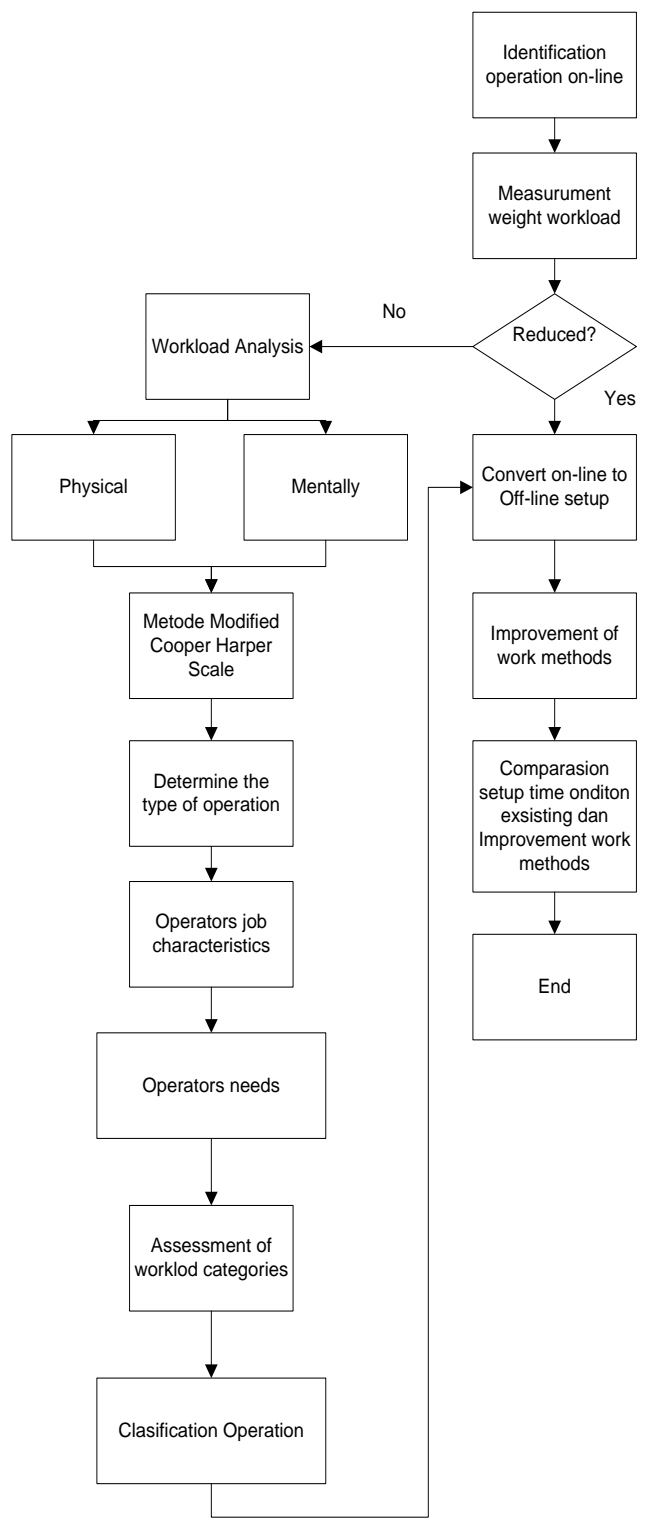

Figure 1. Research Methodology

\section{RESUlt AND DisCUSSION}

\section{A. Measurement of Existing Conditions}

The standard time for setting up a 7-8 color setup with colors is 150 minutes/setup. But after measuring the operation time carried out by the printing and ink operators with a stopwatch time study by observing the entire operation process carried out by 1 operation for 1 operator. However, in existing conditions, there are several operations that are carried out by more than one operator that works in parallel as the operation of dismantling the cylinder or the press roll used in the previous operation process. Allotted 2 operators to work on 1 operation make the setup operation interrupted so that it has an impact on the duration of the setup. In Table 1 is the result of calculating the existing conditions carried out.

TABLE 1. MEASUREMENT RESULTS OF EXISTING CONDITIONS

\begin{tabular}{ccc}
\hline \hline Operator & Setup Time (minutes) & Number of Operations \\
\hline Printing & 118.38 & 29 \\
Ink & 97.55 & 16 \\
\hline \hline
\end{tabular}

From the calculation results, the total duration of setup required is 211.33 minutes.

\section{B. Workload Weight Classification}

In this sub-chapter, the workload will be classified into 3 types of work load, namely Under load / Light 30\% -52\%, Optimal load / Moderate 53\% -74\%, Over load / Weight $75 \%-122 \%$. The weighting of the work load is based on previous research by [13] which divides the work load weight in 4 categories, namely Light $30 \%$ - 52\%, Medium $53 \%-74 \%$, Height $76 \%-98 \%$, and very high $99 \%-122 \%$. But in this study workload weights were categorized into 3 , namely light (Under load), moderate (Optimal load) and heavy (Over load). The workload with the heavy category in this research is a combination of high and very high workload carried out by previous research. And the workload weights are obtained from the scale of the assessment carried out by the operators of the operations carried out in Table 2 is the classification of workload weights based on the operations carried out by operator printing and Table 3 is the classification of workload weights based on the operations carried out by ink operators.

\section{Setup Time Calculation}

In this sub-chapter, the operations will be measured and categorized into under load, moderate or overload category. The first step is the operation conversion process by brainstorming with related parties in this case the production manager. The second step provides an understanding of off-line setup operations / activities wherein this research is confused with research conducted by [5] in the explanation that off-line setup is an operation / activity that takes place when the engine is running, this 
The $1^{\text {st }}$ International Conference on Business and Management of Technology (IConBMT)

August 3rd 2019, Institut Teknologi Sepuluh Nopember, Surabaya, Indonesia

process can be done before or after the engine stops. So that from the understanding of off-line setup and analysis with the parties involved in the setup operation, a number of operations can be done off-line setup. The classification results obtained from the off-line setup are described in
Table 4 and Table 5 . The final stage is obtained by the total setup time after parallelization of the setup operation. Based on the calculation results, the setup time in this condition is 159 minutes 11 seconds.

TABLE 2.

CLASIFICATION WORKLOAD OPERATORS PRINTING

\begin{tabular}{|c|c|c|c|}
\hline No & Operation & $\begin{array}{c}\text { Workload } \\
\text { Weight }\end{array}$ & Category \\
\hline 1 & Receive a schedule from PPIC for printing machines 7 & $17 \%$ & Under load \\
\hline 2 & Prepare a print cylinder. & $50 \%$ & Under load \\
\hline 3 & Prepare a press roll. & $50 \%$ & Under load \\
\hline 4 & Check cylinder number order $=$ cylinder tube number. & $38 \%$ & Under load \\
\hline 5 & Disassemble the cylinder in units $1-8$. & $82 \%$ & Over load \\
\hline 6 & Disassemble the press roll in units $1-8$. & $80 \%$ & Overload \\
\hline 7 & Clean the cylinder & $30 \%$ & Under load \\
\hline 8 & Clean the pres roll. & $31 \%$ & Under load \\
\hline 9 & Lubricate the cylinder surface with oil. & $27 \%$ & Under load \\
\hline 10 & Cylinder packaging. & $40 \%$ & Under load \\
\hline 11 & Packaging pres roll. & $40 \%$ & Under load \\
\hline 12 & Save the cylinder to the warehouse & $28 \%$ & Under load \\
\hline 13 & Save the cylinder to the warehouse & $28 \%$ & Under load \\
\hline 14 & Save the press roll to the warehouse. & $42 \%$ & Under load \\
\hline 15 & Remove the cylinder ass pack on unit 8 . & $80 \%$ & Over load \\
\hline 16 & Install the cylinder in units $1-8$. & $80 \%$ & Over load \\
\hline 17 & Install press roll units $1-8$ & $57 \%$ & Optimal load \\
\hline 18 & Check the type and size of the material whether it is in accordance with the work order.. & $30 \%$ & Under load \\
\hline 19 & Upgrade the material to the machine & $37 \%$ & Under load \\
\hline 20 & Input of raw material diameter to unwind and core rewind on the monitor on each machine. & $32 \%$ & Under load \\
\hline 21 & Remove doctor blade units $1-8$. & $57 \%$ & Optimal load \\
\hline 22 & Take a doctor blade that will be used on the next job. & $20 \%$ & Under load \\
\hline 23 & Measure the length of the cylinder and measure the doctor blade that will be used in the execution of the order. & $52 \%$ & Under load \\
\hline 24 & Install the doctor blade in units $1-8$ & $57 \%$ & Optimal load \\
\hline 25 & Check the engine blower, and ensure the position of the chamber in the open position. & $27 \%$ & Under load \\
\hline 26 & Blame the heater and set the temperature at a temperature of $35-65^{\circ} \mathrm{C}$. & $30 \%$ & Under load \\
\hline 27 & Check and adjust the tension according to the type of raw material and the size of the raw material. & $34 \%$ & Under load \\
\hline 28 & Adjust the printing machine speed according to the type of material to be printed. & $34 \%$ & Under load \\
\hline 29 & Check and adjust the speed and sensor for detecting the movement of materials on the cylinder in each color unit. & $30 \%$ & Under load \\
\hline
\end{tabular}

TABLE 3.

CLASIFICATION WORKLOAD OPERATORS INK

\begin{tabular}{clccc}
\hline \hline No & & Operation & Workload Weight & Category \\
\hline 1 & Prepare ink filters. & $40 \%$ & Under load \\
2 & Prepare a solvent. & $44 \%$ & Under load \\
3 & Preparing ink. & $37 \%$ & Under load \\
4 & Preparing ink reserves. & $44 \%$ & Under load \\
5 & Clean the ink tank. & $83 \%$ & Over load \\
6 & Install the ink filter. & $67 \%$ & Optima lload \\
7 & Prepare the container. & $53 \%$ & Optimal load \\
8 & Mix ink with solvent. & $83 \%$ & Over load
\end{tabular}




\begin{tabular}{cllc}
9 & Measuring ink viscosity. & $37 \%$ & Under load \\
10 & Do color pulls from the previous job & $30 \%$ & Under load \\
11 & Check the color of the ink used in the previous job. & $34 \%$ & Under load \\
12 & Pour ink into the ink tank & $77 \%$ & Over load \\
13 & Install ink magnet & $43 \%$ & Under load \\
14 & Take color draws in each unit and equate with a color pull book. & $40 \%$ & Under load \\
15 & Color Matching & $43 \%$ & Under load \\
16 & Attach color pull paper to each unit & $43 \%$ & Under load \\
\hline \hline
\end{tabular}

\section{Improvement of Work Method}

In this sub-section, an operational evaluation will be carried out that has a workload weighting in the category of overload. The operator allocation for each operation is generally the same, namely 1 operator working on one operation, but there are several operations that must be done simultaneously. For this reason, in this study the evaluation of work methods that are interpreted by two operators will be analyzed by one operator by considering the experience, so that the performance of all operators is equal and stable so that more than one operator has the same time between one operator and another. From the results of analysis carried out using a map of the left hand and right hand, a significant reduction in time was obtained as will be described in Table 6 .

Improvements in work methods pay attention to several operations that can be carried out off-line and changes in operating time after an economic study of meal movements obtained the proposed new sequence of operations carried out by printing and ink operators aimed at each in Figure 3 and Figure 4. Improved sequence of operations working methods affect the duration of setup time. Based on the calculation results, the setup time is 147 minutes 19 seconds. This time is lower than the standard setup time specified by the company which for the setup operation with the number of colors 7-8 colors is 150 minutes / setup. In addition, performance calculations are also carried out under conditions of improvement in work methods. Condition performance after work method repairs for printing operations is $70 \%$ and ink operation is $73 \%$.

Based on Table 2 and Table 3 it can be seen that the workload weights generated using the Modified Cooper Harper (MCH) Scale have 4 overload operations, 3 operations are classified as optimally loaded, and 23 operations are classified as under load or light workload handled by the printing operator. Meanwhile on the ink setup operation there are 3 overload operations or heavy workloads, 6 optimal loads or moderate workloads, and 7 operations that are classified as under loaded.

Based on Table 4 and Table 5, there are 7 operations that can be converted into off-line setup operations carried out by the printing operator for a total time of 26 minutes 11 seconds and 5 operations which can be converted into offline setup operations performed by total printing operators time of 31 minutes 05 seconds. The duration of the offline operation does not affect the duration of the setup time because the offline operation is not a waste operation. So that the printing and ink operation setup process duration is 92 minutes 11 seconds and 66 minutes 50 seconds. The duration of the setup process is obtained from a total reduction in the duration of the setup printing operator's existing conditions and after the operation evaluation is made off-line setup.

TABLE 4.

OPERATION OFF-LINE SETUP OPERATORS PRINTING

\begin{tabular}{|c|c|c|c|}
\hline No & Operation & $\begin{array}{l}\text { Workload } \\
\text { Weight }\end{array}$ & $\begin{array}{c}\text { Time } \\
\text { (minutes) }\end{array}$ \\
\hline 1 & $\begin{array}{l}\text { Receive a schedule from PPIC } \\
\text { for printing machines } 7\end{array}$ & $17 \%$ & 2.21 \\
\hline 2 & Prepare a print cylinder. & $50 \%$ & 5 \\
\hline 3 & Prepare a press roll. & $50 \%$ & 5 \\
\hline 4 & $\begin{array}{l}\text { Check cylinder number order }= \\
\text { cylinder tube number. } \\
\text { Disassemble the cylinder in } \\
\text { units }\end{array}$ & $38 \%$ & 3.15 \\
\hline 5 & $\begin{array}{l}\text { Check the type and size of the } \\
\text { material whether it is in } \\
\text { accordance with the work order }\end{array}$ & $30 \%$ & 3.07 \\
\hline 6 & $\begin{array}{l}\text { Take a doctor blade that will be } \\
\text { used on the next job }\end{array}$ & $20 \%$ & 1.28 \\
\hline 7 & $\begin{array}{l}\text { Measure the length of the } \\
\text { cylinder and measure the } \\
\text { doctor blade that will be used } \\
\text { in the execution of the order. }\end{array}$ & $52 \%$ & 6 \\
\hline
\end{tabular}

TABLE 5.

OPERATION OFF-LINE SETUP OPERATORS INK

\begin{tabular}{clcc}
\hline \hline No & \multicolumn{1}{c}{ Operation } & $\begin{array}{c}\text { Workload } \\
\text { Weight }\end{array}$ & $\begin{array}{c}\text { Time } \\
\text { (minutes) }\end{array}$ \\
\hline 1 & Prepare ink filters. & $40 \%$ & 7.05 \\
2 & Prepare a solvent. & $44 \%$ & 7.1 \\
3 & Preparing ink. & $37 \%$ & 7.02 \\
4 & Preparing ink reserves. & $44 \%$ & 3.15 \\
5 & $\begin{array}{l}\text { Check the color of the ink } \\
\text { used in the previous job. }\end{array}$ & $34 \%$ & 7.18 \\
\hline \hline
\end{tabular}


The $1^{\text {st }}$ International Conference on Business and Management of Technology (IConBMT)

August 3rd 2019, Institut Teknologi Sepuluh Nopember, Surabaya, Indonesia

TABLE 6.

COMPARISON OF SETUP TIME

\begin{tabular}{llc}
\hline \hline Operation & \multicolumn{1}{c}{ Condition } & Setup Time (minutes) \\
\hline Printing & Standard Setup & 150 \\
& Existing & 211,33 \\
\multirow{2}{*}{ Ink } & & \\
& Off-line & 159,11 \\
& MCH-SMED & 143,11 \\
\hline \hline
\end{tabular}

\section{CONCLUSION}

The research results in an SI business strategy, IT business strategy, and IS / IT management strategy and portfolio recommendations that can be implemented at PT. XYZ Surabaya in the future. For the SI business strategy that is produced is adding new applications such as ERP,
CRM Module, Financial System, and Third Party Data Collection Application to support the SI business strategy. Then for the IT strategy the recommendations that emerged were the utilization of cloud computing technology, IPTV, and the addition of infrastructure coverage. While for the IS / IT management strategy at PT. XYZ Surabaya is an ERP application as an integration between departments, cost benefit analysis and performance appraisal. The results of McFarlan's strategic grid analysis for the upcoming application portfolio are two strategic applications, namely CRM and Quality Management System. One high potential application is Perfomance Appraisal. Key operational applications with develop status are ERP, Third Party Data Collection Application and Financial System.

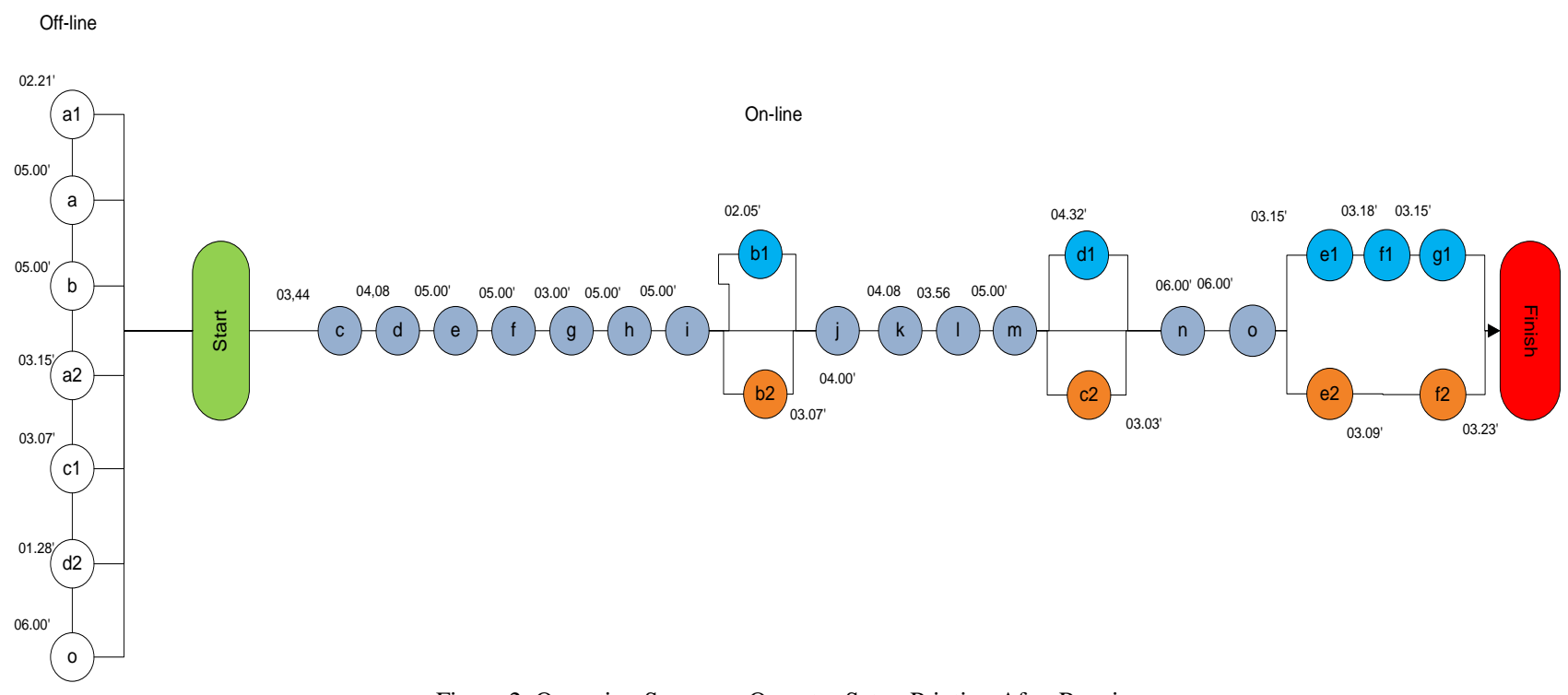

Figure 2. Operation Sequence Operator Setup Printing After Repair.

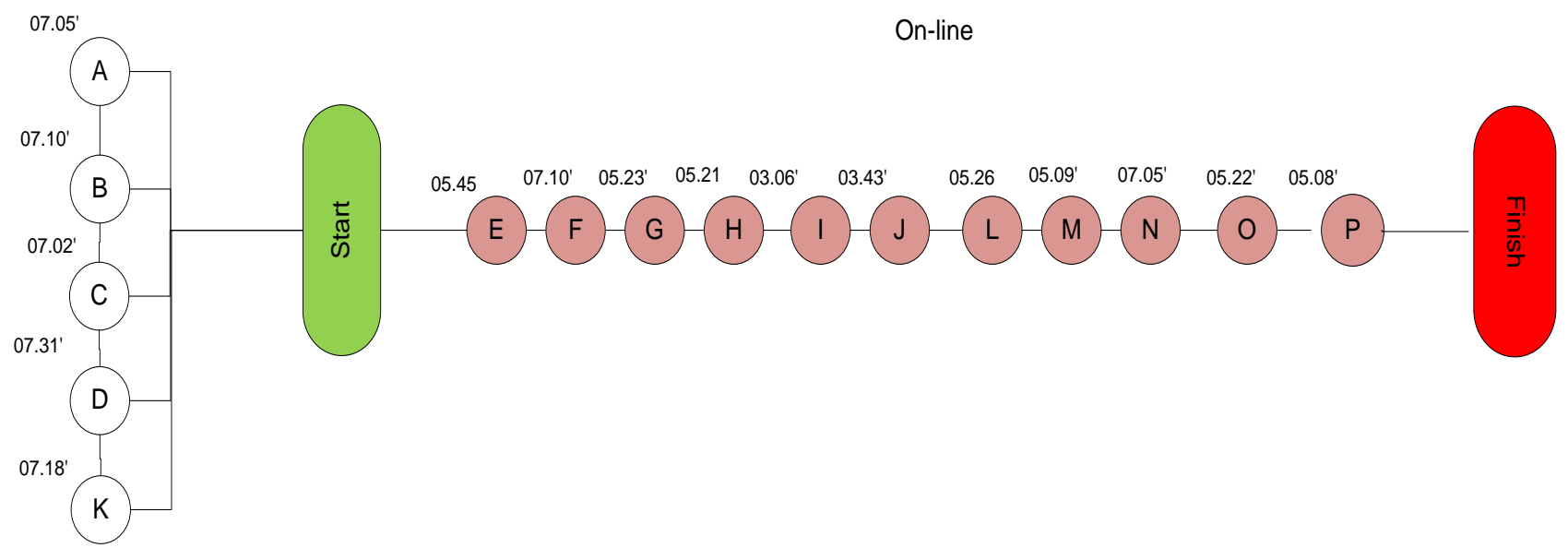

Figure 3. Operation Sequence Operator Setup Ink After Repair. 
The $1^{\text {st }}$ International Conference on Business and Management of Technology (IConBMT)

August 3rd 2019, Institut Teknologi Sepuluh Nopember, Surabaya, Indonesia

\section{REFERENCES}

[1] Koren, Y., Heisel, U., Jovane, F., Moriwaki, T., Pritschow, G., Ulsoy, G., Van Brussel, H., "Reconfigurable manufacturing systems," CIRP Ann. - Manuf. Technol., vol. 48, no. 2, pp. 527540, 1999.

[2] B. Suhardi and D. Satwikaningrum, "Perbaikan waktu setup sengan menggunakan metode SMED," in Seminar Nasional IENACO, 2015, pp. 246-250.

[3] M. Cakmakci, "Process improvement: Performance analysis of the setup time reduction-SMED in the automobile industry," Int. J. Adv. Manuf. Technol., vol. 41, no. 1-2, pp. 168-179, 2009.

[4] L. Chen and B. Meng, "The application of setup reduction in lean production," Asian Soc. Sci., vol. 6, no. 7, pp. 108-113, 2010.

[5] D. Van Goubergen and H. Van Landeghem, "Rules for integrating fast changeover capabilities into new equipment design," Robot. Comput. Integr. Manuf., vol. 18, no. 3-4, pp. 205-214, 2002.

[6] M. Bevilacqua, F. E. Ciarapica, I. De Sanctis, G. Mazzuto, and C. Paciarotti, "A Changeover Time Reduction through an integration of lean practices: A case study from pharmaceutical sector," Assem. Autom., vol. 35, no. 1, pp. 22-34, 2015.
[7] A. Azizi and T. a/p Manoharan, "Designing a future value stream mapping to reduce lead time using SMED-A case study," Procedia Manuf., vol. 2, pp. 153-158, 2015.

[8] A. Azzi, M. Faccio, A. Persona, and F. Sgarbossa, "Lot splitting scheduling procedure for makespan reduction and machine capacity increase in a hybrid flow shop with batch production," Int. J. Adv. Manuf. Technol., vol. 59, no. 5-8, pp. 775-786, 2012.

[9] B. J. Singh and D. Khanduja, "SMED: For quick changeovers in foundry SMEs," Int. J. Product. Perform. Manag., vol. 59, no. 1, pp. $98-116,2010$.

[10] S. Shingō, Revolution in Manufacturing: The SMED System. Cambridge, Massachusetts: Productivity Press, 1985.

[11] R. P. Harper and G. E. Cooper, "Handling qualities and pilot evaluation," J. Guid. Control. Dyn., vol. 9, no. 5, pp. 515-529, 1986.

[12] V. J. Gawron, Human Performance Measures Handbook. Mahwah, New Jersey: Lawrence Erlbaum Associates, 2000.

[13] T. Tarwaka, S. H. A. Bakri, and L. Sudiajeng, Ergonomi untuk Keselamatan dan Kesehatan Kerja dan Produktivitas. Surakarta, Indonesia: UNIBA Press, 2004. 